\title{
Willingness to pay for a quality-adjusted life year for depressive disorders compared to heart disease based on population preferences
}

\author{
Laura Ulbrich ${ }^{1,2}$ (1) $\cdot$ Christoph Kröger ${ }^{1}$ \\ Accepted: 18 January 2021 / Published online: 15 February 2021 \\ (c) The Author(s) 2021
}

\begin{abstract}
Purpose According to estimations of the World Health Organization, depressive disorders, and cardiovascular disease will be the leading causes for global burden of disease in 2030. The aim of the present study was to estimate the value a representative sample of the German population places on quality-adjusted life years (QALYs) for depressive disorders compared to heart disease.

Methods A representative sample of $N=967$ of the German general public was randomly presented with one of two hypothetical health-loss scenarios: One version of the questionnaire presented respondents with health loss due to depression, while the other version dealt with health loss due to experiencing a heart disease. Respondents were asked to indicate their willingness to pay (WTP) for four hypothetical health-gain scenarios with different treatment options.

Results In the depression questionnaire median WTP values ranged from 1000 to $1500 \mathrm{EUR}$; in the heart disease questionnaire from 1000 to 2000 EUR. Results of the Mann-Whitney $U$-Test and Median Test indicate higher WTP values for heart disease compared to depressive disorders when QALY gains were minor and stretched over a long period of time, and when treatment with bypass operation (rather than treatment with ECT) was offered. Zero WTP was significantly higher in all scenarios of the depression questionnaire in comparison to the hearth disease questionnaire.

Conclusion Results indicate that respondents valued the necessity of paying for treatment higher when presented with heart disease compared to depression.
\end{abstract}

Keywords Willingness to pay $\cdot$ Quality-adjusted life year $\cdot$ Health utility $\cdot$ Depression $\cdot$ Heart disease

\section{Introduction}

In the healthcare sector, with its limited resource settings, cost-effectiveness analyses are important in terms of input to decision-making; they are used as guidelines in priority setting, resource allocation, and reimbursement decisions. The preferred metric of health benefits in cost-effectiveness analyses and measure of years lived in full health is the measure of quality-adjusted life years (QALYs) [1, 2]. It combines the impact of health changes on both, healthrelated quality of life and quantity of life years and facilitates

Laura Ulbrich

laura.ulbrich@uni-hildesheim.de

Department of Psychology, University of Hildesheim, Hildesheim, Germany

2 Department of Clinical Psychology and Psychotherapy, University of Hildesheim, Universitätsplatz 1,

31141 Hildesheim, Germany the comparison of different interventions within a disease or in comparison with other diseases [3]. Measuring preferences for health improvements, the demand-side value of a person's willingness to pay (WTP) in gaining a QALY is one relevant component in the interpretation of the results from health economic evaluations [1]. Several studies have tried to estimate the value of a QALY through WTP method (e.g., [3-5]). In a study across nine European countries ('Euro VaQ study'), a total of $N=17,657$ respondents was presented with different hypothetical health-gain scenarios and asked to state their WTP. Median WTP per QALY values ranged from $\$ 1100$ to $\$ 2300$ [3]. A systematic review including 24 studies on WTP per QALY found that WTP estimates range from $€ 1000$ to $€ 4,800,000$, with median WTP of $€ 24,226$ per QALY. The authors conclude that WTP per QALY seems to be related to several different contextual factors (e.g., size and type of QALY gain valued) and that the assumption that "a QALY is a QALY is a QALY" seems to be untenable [6]. A recent study of WTP per QALY in Japan came to a similar 
conclusion, that the use of a uniform price threshold may not reflect diverse preferences, which seem to be based on several factors, such as illness type and severity [7].

\section{Global burden of disease}

Estimations of the World Health Organization (WHO) predict unipolar depression to be the leading cause of GBD in 2030, followed by coronary heart disease [8]. A measure quantifying the burden of a disease in terms of mortality and morbidity is the measure of disability-adjusted life years (DALYs). DALYs for a disease or health condition are calculated as the sum of the years of life lost (YLL) due to premature mortality in the population, and the years lost due to disability (YLD) for people living with the health condition or its consequences [9]. The number of all-age YLDs attributed to depressive disorders has increased tremendously over the past decades: depressive disorders are among the three leading causes of YLD [10] and DALYs [11]. Cardiovascular diseases (CVDs), a group of disorders of the heart and blood vessels [12], is estimated to be the leading cause of mortality and morbidity worldwide [13]. In 2016, 17.9 million people died due to cardiovascular diseases, and $85 \%$ of these deaths were due to a heart attack [14]. In addition to the personrelated burden of a disease, the economic burden can be estimated in terms of direct costs (e.g., costs of hospitalization, psychotherapy, medication) and indirect costs (e.g., reduced productivity and disability insurance; for example, see [15]). For the United States, the total economic burden of cardiovascular diseases is estimated at $\$ 320.1$ billion [16] and the economic burden of major depressive disorder was estimated at $\$ 210.5$ billion [17].

To date, no study has attempted to quantitatively assess the degree to which a European population values a QALY gain for a specific physical illness in comparison to a QALY gain for a specific mental disorder, which would allow comparison between both health-gain values. As potential recipients of medical services and payers of social insurance contributions, it would be desirable to know the value a representative population sample places on QALY gains for mental and physical health [4].

\section{Study aims}

The aim of the present study was to investigate the value a representative sample of the German population ${ }^{1}$ places on QALY gains for mental and physical health. Respondents

\footnotetext{
$\overline{1}$ Germany has a universal health care system with two types of health insurance: Germans can choose between public (statutory) or private health insurance, which are co-financed by employer and employee. As of today, no threshold per QALY exists.
}

were presented with one of two surveys and were asked to indicate their WTP for different scenarios offering QALY gains regarding a depressive episode or a heart disease. We hypothesize:

(1) that WTP per QALY is higher in all presented scenarios of the heart disease questionnaire in comparison to the equivalent scenarios of the depression questionnaire and;

(2) that zero WTP is higher in all scenarios of the depression questionnaire compared to the heart disease scenarios.

Additionally, to investigate if the results from the EuroVaQ study are applicable to the presented illness-specific scenarios, we tested if the differences in mean WTP are significant across selected questions for respondents answering each respective pair of questions. The scenario-specific hypotheses are specified after introducing the illness-specific scenarios in "Health gains valued" section.

\section{Method}

\section{Questionnaire}

Question feasibility and validity were examined by pilot respondents $(n>10)$, who were asked to comment on the clarity of the presented scenarios. Their feedback was used to improve the wording of the health state descriptions and the presentation of the questions.

On the first page of the survey, respondents were informed about the objective of the study and had to give consent to start the questionnaire. Respondents were introduced to the hypothetical scenario that no sickness funds exist in Germany and that therefore, they would not have to pay premiums or contributions for health insurance. Instead, they would have to pay for every medical service out of their own pocket and had saved money for such medical expenditures.

The concept of measuring health on a visual analog scale was introduced, and generic health-state descriptions were used to indicate different levels of health on the scale. These consisted of three European Quality of Life 5 Dimensions 3 Level Version (EQ-5D-3L [18]) health states, and numerical valuations derived from survey values [19] to ensure comparability to the EuroVaQ questionnaire. The respondents were then asked to answer various demographical questions (e.g., age, income, health insurance), to estimate their life expectancy, and to rate their current health on a visual analogue scale (European Quality of Life Visual Analogue Scale (EQ-VAS [18])) with values between 0 and 100. The Patient Health Questionnaire (PHQ-2 [20]) and EQ-5D-3L [18] were used to briefly assess symptoms of depression and 
100

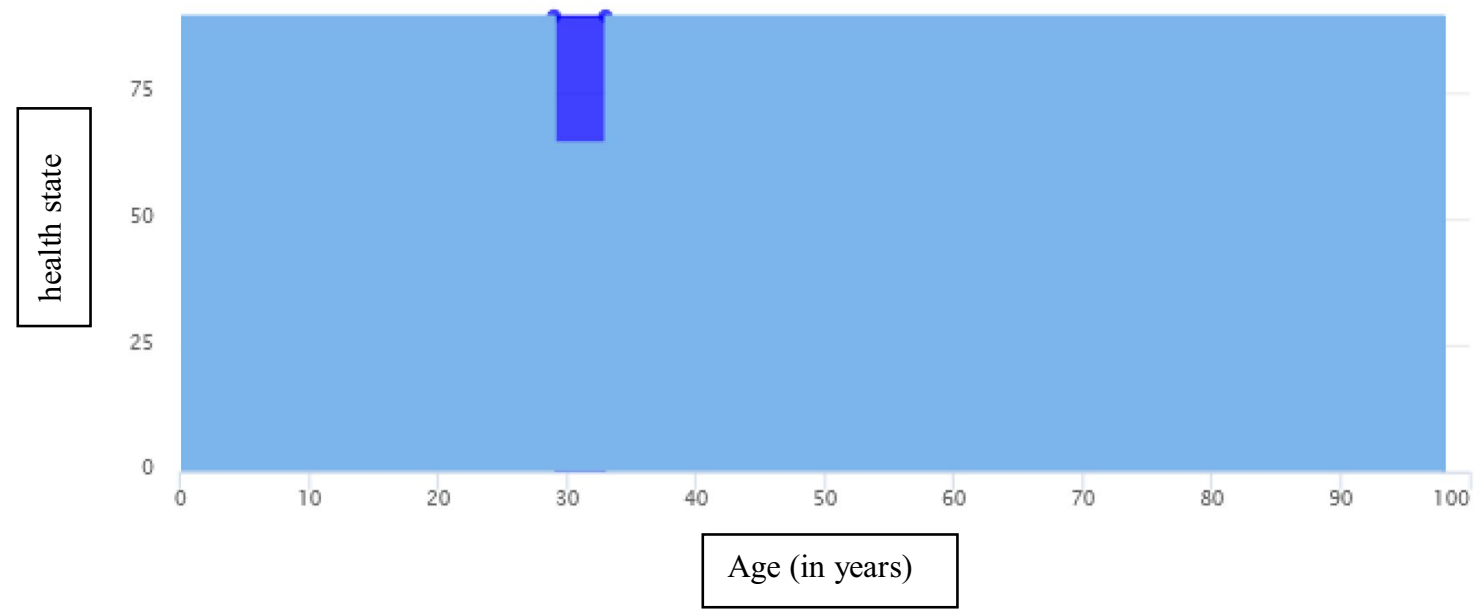

Fig. 1 Example of a health gain scenario (Scenario A). The scenario is tailored to respondent's age, health state and life expectancy. This figure shows a 28 -year-old with a life expectancy of 98 years (on the $x$-axis) and a current health state of 90 points (out of 100; on the $y$-axis). The respondent is presented with a loss in quality of life of minus 25 points in one year's time for a period of 4 years. If the respondent would be willing to pay for treatment his/her health could be restored (dark blue) and s/he would live his/her life at the current health state until his/her expected death

was willing to pay and the minimum that he or she was not willing to pay, the respondent was asked to state his or her maximum WTP in an open-ended response. If the respondent answered that she or he was not willing to pay money to avoid health loss, he or she was asked to indicate one of numerous reasons from a set of pre-coded responses, or by using a free text option. These statements were directly translated from the EuroVaQ questionnaire [3, 21]. The remaining three scenarios were presented in a similar manner. The sequence and translation of one exemplary scenario is presented in Online Resource 2. Lastly, respondents were asked to rate how much they currently knew about the treatment method of electroconvulsive therapy (in the depression questionnaire) or bypass operation (in the heart disease questionnaire) and were asked to state whether they thought this method was adequate. Respondents were given the chance to view all their answers on one page, and to validate or change their answers.

\section{Health gains valued}

Respondents were presented with health gains of either one QALY (scenarios A and B) or a fraction of a QALY (scenarios $\mathrm{C}$ and $\mathrm{D}$ ). All scenarios are in the style of the EuroVaQ scenarios. An overview of the four scenarios can be found in Table 1.

To test for differences across scenarios, we investigated the following hypothesis (holding the illness-specific context constant): 
Table 1 Health gains valued for the two questionnaire versions

\begin{tabular}{|c|c|c|c|c|c|}
\hline Scenario description & Health loss & Duration & Point in time & $\begin{array}{l}\text { Health gain through } \\
\text { treatment }(\%)\end{array}$ & Treatment \\
\hline \multicolumn{6}{|c|}{ Questionnaire version: depression } \\
\hline Scenario A & 25 points & 4 years & In 1 year & 100 & Pain-free treatment \\
\hline Scenario B & 10 points & 10 years & In 1 year & 100 & Pain-free treatment \\
\hline Scenario C & 25 points & 4 years & In 1 year & 90 & Inpatient treatment ( 8 weeks) \\
\hline Scenario D & 25 points & 4 years & In 1 year & 90 & $\begin{array}{l}\text { Inpatient treatment ( } 8 \text { weeks) } \\
\text { plus electroconvulsive } \\
\text { therapy }\end{array}$ \\
\hline \multicolumn{6}{|c|}{ Questionnaire version: heart disease } \\
\hline Scenario A & 25 points & 4 years & In 1 year & 100 & Pain-free treatment \\
\hline Scenario B & 10 points & 10 years & In 1 year & 100 & Pain-free treatment \\
\hline Scenario C & 25 points & 4 years & In 1 year & 90 & Inpatient treatment ( 8 weeks) \\
\hline Scenario D & 25 points & 4 years & In 1 year & 90 & $\begin{array}{l}\text { Inpatient treatment ( } 8 \text { weeks) } \\
\text { plus bypass operation }\end{array}$ \\
\hline
\end{tabular}

Hypothesis 3 Mean WTP is significantly higher in scenario A compared to scenario B in both questionnaire versions.

Hypothesis 4 Mean WTP is significantly higher in scenario $\mathrm{D}$ compared to scenario $\mathrm{C}$ in both questionnaire versions.

\section{Recruitment of subjects}

Respondents were recruited from an Internet panel run by USUMA GmbH (http://www.usuma.com). The survey was launched on March 6, 2019 and closed on March 25, 2019. To achieve representativeness of the German general public by age, gender, socioeconomic status and region both within and across the total sample, respondents were allocated to one of the two questionnaire versions randomly until quotas for socio-demographic characteristics were achieved.

\section{Exclusion criteria}

To ensure that the questions were relevant to the individual respondents, and to ensure comparability to the EuroVaQ report, the following exclusion criteria were applied: Respondents were excluded from all data analysis if (a) their health state was less than 20 points, and (b) their life expectancy was less than 6 years. Additionally, respondents were excluded from data analysis regarding scenarios A, C, and D if (c) they rated their health state at less than 35 points, and excluded from data analysis regarding scenario B if (d) life expectancy was assumed to be below 12 years. The intention was to ensure that no health loss reduced the respondent's health to below 10 points and that all health gains were complete at least 1 year before the respondent expected to die. A total of five respondents were excluded based on the following reasons: respondents indicating an implausibly high number of people living in the household $(n=3)$ and an implausible age $(n=2)$. The flowchart in Fig. 2 shows the process of data analysis. The primary analysis reported here has been undertaken on the set of complete answers. As is conventional in WTP studies, 'protest respondents' who were not willing to pay to avoid health loss for the sole reason that "the government should pay" were excluded, because the respondents did not seem to understand the hypothetical nature of the question (see [3, 4, 21, 22]).

\section{Data analysis}

All analyses was undertaken in IBM SPSS Statistics 26. Using open-ended questions allowed determination of the mean and median values reported for each scenario. WTP values were collected in 2019 Euros and are also reported in US dollars to facilitate international comparability. In accordance with the standard procedure in WTP studies, we report trimmed means and medians (excluding the top $1 \%$ of WTP responses) to reduce the impact of extreme, possibly implausible upper-end responses.

The Kolmogorov-Smirnoff test was used to test the assumption of normal distribution. WTP scores for scenario $\mathrm{A}(D(629)=0.450, p<0.001)$, scenario $\mathrm{B}(D(570)=0.393$, $p<0.001)$, scenario $\mathrm{C}(D(563)=0.432, p<0.001)$, and scenario $\mathrm{D}(D(514)=0.430, p<0.001)$ all differed significantly from normal. Because of unmet normality assumption, biascorrected and accelerated $95 \%$ confidence intervals around means were estimated using a two-stage bootstrapping routine $[23,24]$. To reduce the impact of outliers on results, and because of the skewed distribution, the nonparametric Mann-Whitney $U$-test and Median test were used to assess whether responses differed by questionnaire version (i.e., depression questionnaire vs. heart disease questionnaire) on WTP per QALY. Effect size $r$ was calculated [24, 25]. To test hypothesis 2-whether the likelihood of expressing 


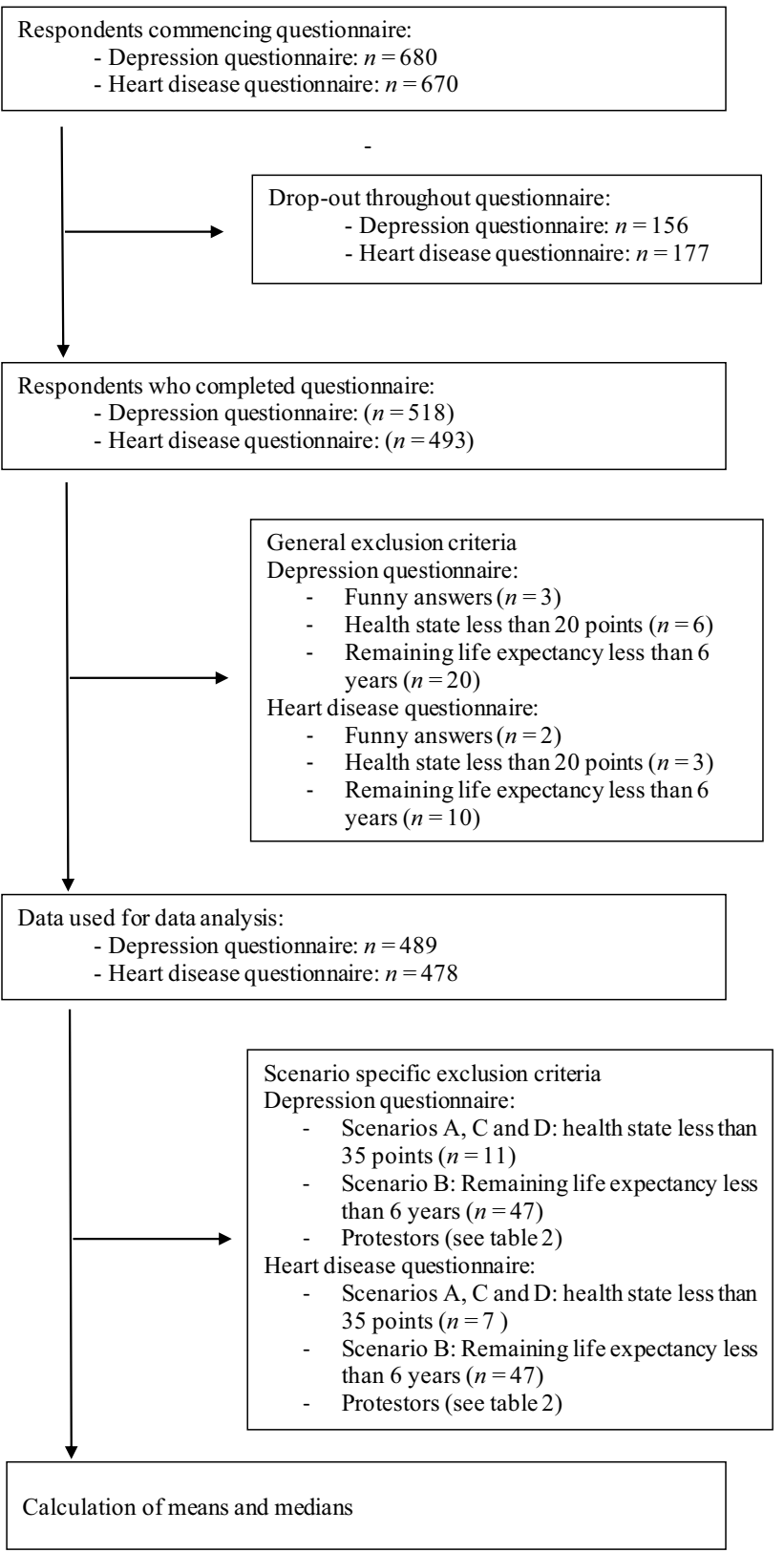

Fig. 2 Flowchart

a positive WTP differed across questionnaire versionsWTP responses were dichotomized as zero and non-zero values, and Pearson's chi-square tests and odds ratios were calculated for all scenarios. To analyze whether mean WTP responses differed significantly across scenarios (holding the illness-specific context constant), paired $t$-tests for the respective question pairs were conducted. A Bonferroni corrected $\alpha\left(P_{\text {crit }}=\alpha / k=0.05 / 2=.025\right)$ was applied. A logistic regression was used to investigate the effects of respondent's characteristics (age, sex, income, educational level, current health state and PHQ-2 score) on the likelihood of indicating positive WTP.

\section{Results}

A total of 967 respondents answered each of the four questions across the two questionnaire versions. Dropout rates were $23 \%$ for the depression questionnaire and $26 \%$ for the heart disease questionnaire and were comparable to dropout rates for other surveys from this company. Most respondents $(9.7 \%)$ dropped out immediately after reading about the objective of the study and before giving consent. No effect of gender, age or health status was found on drop-out. Respondents' characteristics are displayed in Table 2. The final sample was broadly representative of the German general public. The mean age of the respondents was 48.52 years, and $49.94 \%$ were male. No between-group differences were found in terms of sociodemographic data and the frequencies of pre-existing conditions (i.e., mental disorders, heart disease). Table 3 reports number of respondents, number of zero WTP, and number of protestors by questionnaire version.

Trimmed median, mean, and maximum WTP values and $95 \%$ confidence intervals around trimmed means are reported in Table 4. In the depression questionnaire, median WTP values ranged from $€ 1000$ to $€ 1500$. In the heart disease questionnaire, median WTP ranged from $€ 1000$ to $€ 2000$. Untrimmed WTP values are reported in Online Resource 3.

Results from the Mann-Whitney U-Tests and Median test indicate significant differences in distribution across questionnaire versions in scenario $\mathrm{B}(U=29,065, z=-2.259$, $p=0.024, r=-0.099)$ and scenario $\mathrm{D}(U=26,213$, $z=-3.064, p=0.002, r=-0.136)$. In scenario $\mathrm{C}$, both the Mann-Whitney U-Test and Median test indicated that WTP per QALY regarding heart disease $(M d n=€ 1500)$ did not significantly differ from the equivalent depression scenario $(M d n=€ 15,000 ; U=36,262, z=-0.905, p=0.366$, $r=-0.038)$. For scenario A, the Mann-Whitney $U$-test indicated significant differences $(U=43,107, z=-2.399$, $p=0.016, r=-0.096)$, whereas the Median test showed no significant differences between the depression questionnaire $(M d n=€ 1000)$ and the heart disease questionnaire (Mdn $=€ 1500 ; p=0.051)$.

Examining hypothesis 2, Pearson's chi-square test indicated that there were significant associations between questionnaire version and zero WTP in all scenarios (Scenario $\mathrm{A}:\left(\chi^{2}(1)=7.66, p=0.006\right)$; scenario $\mathrm{B}:\left(\chi^{2}(1)=22.14\right.$, $p<0.001)$; scenario $\mathrm{C}\left(\chi^{2}(1)=23.41, p<0.001\right)$; and scenario $\mathrm{D}\left(\chi^{2}(1)=35.75, p<0.001\right)$. Reasons stated for zero WTP are tabulated in Table 5. Odds ratios presented in Table 6 show that the odds of indicating zero WTP were 1.5 times (scenario A) to 2.3 times (scenario D) higher in the depression scenarios compared to the corresponding heart disease scenarios. 
Table 2 Respondents' characteristics

\begin{tabular}{|c|c|c|c|c|}
\hline \multirow[t]{2}{*}{ Characteristic } & \multicolumn{2}{|c|}{$\begin{array}{l}\text { Questionnaire: heart disease } \\
N=478\end{array}$} & \multicolumn{2}{|c|}{$\begin{array}{l}\text { Questionnaire: depression } \\
N=489\end{array}$} \\
\hline & $M(\mathrm{SD})$ & Min/max & $M(\mathrm{SD})$ & $\operatorname{Min} / \max$ \\
\hline Age (in years) & $48.68(16.89)$ & $18 / 89$ & $48.35(17.09)$ & $18 / 83$ \\
\hline Size of household & $2.5(1.24)$ & $1 / 9$ & $2.27(1.11)$ & $1 / 6$ \\
\hline Number of children & $1.02(1.16)$ & $0 / 7$ & $.95(1.11)$ & $0 / 6$ \\
\hline Life expectancy ${ }^{\mathrm{a}}$ (age) & $83.11(9.94)$ & $30 / 150$ & $83.39(10.76)$ & $40 / 150$ \\
\hline \multirow[t]{2}{*}{ Own health $(20-100)$} & $79.87(16.44)$ & $20 / 100$ & $80.24(16.78)$ & $20 / 100$ \\
\hline & $n$ & $\%$ & $n$ & $\%$ \\
\hline 20 to 69 (poor) & 88 & 18.4 & 85 & 17.4 \\
\hline 70 to 79 (rather poor) & 69 & 14.4 & 78 & 16.0 \\
\hline 80 to 89 (rather good) & 127 & 26.6 & 109 & 22.2 \\
\hline 90 to 100 (very good) & 194 & 40.6 & 217 & 44.4 \\
\hline Low remaining lifetime (less than 16 years) & 89 & 18.1 & 88 & 18.0 \\
\hline Males (rather than females) & 230 & 48.1 & 253 & 51.7 \\
\hline \multicolumn{5}{|l|}{ Educational level } \\
\hline Low (up to 10 years of schooling) & 71 & 14.8 & 83 & 17.0 \\
\hline Medium (10 years of schooling) & 165 & 34.5 & 155 & 31.7 \\
\hline High (additional 3 years of advanced education) & 233 & 48.7 & 245 & 50.1 \\
\hline \multicolumn{5}{|l|}{ Family status } \\
\hline Single & 158 & 33.1 & 170 & 34.8 \\
\hline Married & 228 & 47.7 & 229 & 46.8 \\
\hline Divorced & 49 & 10.3 & 51 & 10.4 \\
\hline Widowed & 30 & 6.3 & 13 & .03 \\
\hline \multicolumn{5}{|l|}{ Income (monthly net household income $€$ ) } \\
\hline No answer & 23 & 4.8 & 22 & 4.5 \\
\hline Below $500 €$ & 8 & 1.7 & 11 & 2.2 \\
\hline 500 to below $1.000 €$ & 42 & 8.8 & 37 & 7.6 \\
\hline $1.000 €$ to below $1.500 €$ & 51 & 10.7 & 55 & 11.2 \\
\hline $1.500 €$ to below $2.000 €$ & 68 & 14.2 & 68 & 13.9 \\
\hline $2.000 €$ to below $3.000 €$ & 134 & 28.0 & 127 & 26.0 \\
\hline $3.000 €$ to below $4.000 €$ & 87 & 18.2 & 96 & 19.6 \\
\hline $4.000 €$ and more & 64 & 13.4 & 73 & 14.9 \\
\hline \multicolumn{5}{|l|}{ Health insurance } \\
\hline No answer & 1 & .2 & 2 & .4 \\
\hline Public insurance & 421 & 88.1 & 430 & 87.9 \\
\hline Private insurance & 56 & 11.7 & 56 & 11.5 \\
\hline \multicolumn{5}{|l|}{ Pre-existing conditions } \\
\hline Heart disease (yes rather than no) & 45 & 9.4 & 46 & 9.4 \\
\hline Mental disorder (yes rather than no) & 96 & 20.1 & 104 & 21.3 \\
\hline
\end{tabular}

$M$ mean, $S D$ standard deviation, Min/Max minimum/maximum, $N$ sample size

${ }^{a}$ Excluding respondents with a life expectancy of less than 6 years

Results of the paired $t$-tests are presented in Table 7. Presenting respondents with the heart disease scenario, respondents were willing to pay significantly more money for an 8-week inpatient treatment including bypass operation (scenario D) compared to an 8-week inpatient treatment only (scenario C). No significant differences were found between scenarios $\mathrm{A}$ and $\mathrm{B}$ for both questionnaire versions and between scenarios $\mathrm{C}$ and $\mathrm{D}$ in the depression questionnaire.

Assessing the effects of respondents' characteristics on the likelihood of indicating a positive WTP, only income was found to have a significant effect on respondents' WTP in the depression questionnaire, whereas in the heart disease 
Table 3 Number of respondents, zero WTP and protestors

Scenario description $\quad n^{\mathrm{a}} \quad n$ zero WTP $(\%) \quad n$ protestors (\%)

Questionnaire version: depression

$\begin{array}{llll}\text { Scenario A } & 478 & 190(39.7) & 32(6.7) \\ \text { Scenario B } & 442 & 215(48.6) & 29(6.6) \\ \text { Scenario C } & 478 & 240(50.2) & 43(9.0) \\ \text { Scenario D } & 478 & 270(56.5) & 39(8.2)\end{array}$

Questionnaire version: heart disease

\begin{tabular}{llll} 
Scenario A & 472 & $145(30.7)$ & $25(5.3)$ \\
Scenario B & 432 & $147(34.0)$ & $30(6.9)$ \\
Scenario C & 472 & $157(33.3)$ & $25(5.3)$ \\
Scenario D & 472 & $177(37.5)$ & $34(7.2)$ \\
\hline
\end{tabular}

${ }^{a}$ Excluding respondents who met exclusion criteria (a) to (d) but including protestors questionnaire, a male gender and a higher educational level were associated with a higher likelihood of expressing a positive WTP.

\section{Discussion}

To the author's knowledge, the present study is the first one that compares the value a population-representative sample places on mental versus physical health, in this case, relief from depression or relief from heart disease. Health-gain scenarios customized to fit respondents' characteristics allowed us to present hypothetical scenarios in a personally relevant matter to a large population representative sample. In the depression questionnaire, median

Table $4 * * 1 \%$ trimmed mean, median and maximum values by scenario and questionnaire version excluding 'protest respondents' in Euros

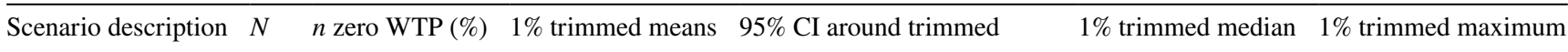
means

Questionnaire version: depression

$\begin{array}{lllllll}\text { Scenario A } & 443 & 158(35.7) & 3451(4170) & 2665-4348(3220-5254) & 1000(1209) & 85,000(102,706) \\ \text { Scenario B } & 410 & 187(45.6) & 2892(3494) & 2172-3730(2624-4507) & 1000(1209) & 50,000(60,415) \\ \text { Scenario C } & 432 & 197(45.6) & 3610(4362) & 2892-4461(3494-5391) & 1500(1814) & 50,000(60,415) \\ \text { Scenario D } & 436 & 231(53.0) & 3011(3638) & 2215-3938(2677-4759) & 1000(1209) & 60,000(72,504)\end{array}$

Questionnaire version: heart disease

\begin{tabular}{llllclll} 
Scenario A & 444 & $120(27.3)$ & $7676(9283)$ & $5434-10,358(6,569-12,522)$ & $1500(1814)$ & $300,000(362,670)$ \\
Scenario B & 399 & $117(29.3)$ & $5766(6971)$ & $4222-7591(5104-9177)$ & $1000(1209)$ & $150,000(181,335)$ \\
Scenario C & 444 & $132(29.7)$ & $5832(7050)$ & $4624-7137(5590-8628)$ & $1500(1814)$ & $150,000(181,335)$ \\
Scenario D & 435 & $143(32.9)$ & $6844(8274)$ & $5567-8316(6730-10,053)$ & $2000(2418)$ & $150,000(181,335)$ \\
\hline
\end{tabular}

WTP values in U.S. $\$$ are in parentheses. Values in $€$ were converted to U.S. $\$$ at the rate of $1 €=\$ 1.2084$ on December 10 th, 2020 $n$ sample size. $C I$ confidence interval

Table 5 Frequencies of reasons for zero WTP

\begin{tabular}{|c|c|c|c|c|c|c|c|c|}
\hline Scenario & $N$ zero WTP & $\begin{array}{l}\text { It wouldn't be } \\
\text { so bad/I could } \\
\text { live with it }\end{array}$ & $\begin{array}{l}\text { Effects of treat- } \\
\text { ment are too } \\
\text { small }\end{array}$ & $\begin{array}{l}\text { I want my fam- } \\
\text { ily to have the } \\
\text { money instead }\end{array}$ & $\begin{array}{l}\text { I would get } \\
\text { better without } \\
\text { treatment }\end{array}$ & $\begin{array}{l}\text { I value the } \\
\text { treatment but } \\
\text { can't afford it }\end{array}$ & $\begin{array}{l}\text { I value treat- } \\
\text { ment but } \\
\text { government } \\
\text { should pay }\end{array}$ & Other reasons \\
\hline \multicolumn{9}{|c|}{ Questionnaire version: depression } \\
\hline A & $190(39.7)$ & $43(9.0)$ & $25(5.2)$ & $18(3.7)$ & $30(6.3)$ & $31(6.5)$ & $32(6.7)$ & $8(1.7)$ \\
\hline $\mathrm{B}$ & $215(48.6)$ & $61(13.8)$ & $39(8.8)$ & $13(2.9)$ & $36(8.1)$ & $36(7.4)$ & $29(6.6)$ & $5(1.1)$ \\
\hline $\mathrm{C}$ & $240(50.2)$ & $48(9.8)$ & $42(8.8)$ & $19(4.0)$ & $35(7.3)$ & $34(7.1)$ & $43(9.0)$ & $16(3.4)$ \\
\hline $\mathrm{D}$ & $270(56.5)$ & $47(9.8)$ & $51(10.7)$ & $15(3.1)$ & $45(9.4)$ & $30(6.3)$ & $39(8.2)$ & $41(8.6)$ \\
\hline \multicolumn{9}{|c|}{ Questionnaire version: heart disease } \\
\hline A & $145(30.7)$ & $21(4.4)$ & $15(3.2)$ & $21(4.4)$ & $13(2.8)$ & $36(7.6)$ & $25(5.3)$ & $14(2.9)$ \\
\hline $\mathrm{B}$ & $147(34.0)$ & $25(5.8)$ & $23(5.3)$ & $12(2.8)$ & $24(5.6)$ & $26(6.0)$ & $30(6.9)$ & 7 (1.6) \\
\hline $\mathrm{C}$ & $157(33.3)$ & $29(6.1)$ & $22(4.7)$ & $13(2.8)$ & $24(5.1)$ & $33(7.0)$ & $25(5.3)$ & $11(2.3)$ \\
\hline $\mathrm{D}$ & $177(37.5)$ & $22(4.7)$ & $26(5.5)$ & $15(3.2)$ & $24(5.1)$ & $39(8.3)$ & $34(7.2)$ & 17 (3.6) \\
\hline
\end{tabular}

Percentages are in parentheses

$N$ sample size 
Table 6 Results of Pearson's chi-square test and odds ratios for zero WTP for depression questionnaire

\begin{tabular}{lrl}
\hline Scenario & \multicolumn{1}{c}{$\chi^{2}$} & OR \\
\hline $\mathrm{A}$ & $7.66^{* *}$ & 1.49 \\
$\mathrm{~B}$ & $22.14^{* *}$ & 1.99 \\
$\mathrm{C}$ & $23.41^{* *}$ & 1.98 \\
$\mathrm{D}$ & $35.75^{* *}$ & 2.29 \\
\hline
\end{tabular}

$O R$ odds ratio

${ }^{* *} p<.01$

values ranged from $€ 1000$ to $€ 1500$; in the heart disease questionnaire from $€ 1000$ to $€ 2000$. Median differences between questionnaire versions were significant in scenarios B and D: It seems that respondents valued QALY gains for cardiovascular health higher compared to QALY gains for depression, when QALY gains were minor and stretched over a long period of time and when treatment with bypass operation (rather than treatment with ECT) was offered. Additionally, results regarding hypothesis 4 indicate that respondents were willing to pay significantly more money for an additional bypass operation in the heart disease questionnaire (scenario D) compared to an eightweek inpatient treatment alone (scenario C). However, no significant differences were found for the equivalent scenarios in the depression questionnaire. Respondents indicated a WTP approximately twice as high for an 8-week inpatient treatment with a bypass operation for heart disease compared to the equivalent depression scenario with ECT. Although the effectiveness of ECT is recognized by the American Psychiatric Association and similar organizations in Germany [26], the rate of ECT use is particularly low in Germany (3.5 per 100,000 inhabitants, compared to 41 per 100,000 inhabitants in Sweden and Belgium [27-29]) and ECT is still offered in less than 50\% of Germany's psychiatric clinics [30]. Interestingly, comparing scenarios A from the assessed health gain scenarios to the equivalent, but generally presented scenario of the EuroVaQ study [3], median WTP values were lower in the depression questionnaire ( $\$ 1176$, compared to $\$ 1532$ in

scenario A of the EuroVaQ study), but comparably higher in the heart disease questionnaire ( $\$ 1763$, compared to \$1532).

The number of respondents indicating zero WTP was significantly higher in all scenarios of the depression questionnaire in comparison to the heart disease questionnaire and the odds of indicating zero WTP were up to 2.3 times higher in the depression scenarios. According to the stated reasons for zero WTP-in the depression questionnaire: "It wouldn't be so bad/I could live with it"; in the heart disease questionnaire: "I value the treatment but can't afford it"- the necessity of treating a somatic disease, i.e., heart disease, seems to be more prevalent than the necessity of treating a mental disorder, i.e., depression. To date, although depression is one of the most dire, and common global health problems, mental disorders are still associated with stigmatization [31]. In a sample of college-aged individuals, less than $25 \%$ of individuals who met the criteria for a mental disorder had sought treatment within the past year [32]. Approximately $70 \%$ of people who experience a mental disorder do not seek healthcare treatment [33]. Factors contributing to the gap between true and treated prevalence include lack of knowledge about the symptoms and how to seek treatment, as well as fear due to anticipated or real acts of discrimination against those with a diagnosed mental disorder [34]. In conclusion, fear of stigmatization, lack of knowledge about the symptoms of depressive disorders and their impact on quality of life, and ignorance of the treatment options may be relevant factors associated with indicating zero WTP to the treatment of depression.

\section{Limitations}

Studies have shown that WTP valuations are highly sensitive to framing effects (e.g., [35]). We tried to address such framing effects by maximizing comparability to the EuroVaQ questionnaire [3] in terms of order and wording of the scenarios and using the same contingent valuation
Table 7 Mean withinrespondent differences in values between question pairs (holding illness-specific context constant)

\begin{tabular}{|c|c|c|c|c|}
\hline Scenarios compared & $n^{\mathrm{a}}$ & Mean difference & $95 \% \mathrm{CI}$ & $\begin{array}{l}p \text {-value for } \\
\text { paired } t \text {-test }\end{array}$ \\
\hline \multicolumn{5}{|c|}{ Questionnaire version: depression } \\
\hline Scenario A-scenario B & 221 & 1438 & -25 to 2901 & .054 \\
\hline Scenario C-scenario D & 181 & 357 & 35 to 679 & .030 \\
\hline \multicolumn{5}{|c|}{ Questionnaire version: heart disease } \\
\hline Scenario A-scenario B & 278 & 9604 & -4357 to 23,566 & .177 \\
\hline Scenario C-scenario D & 269 & -841 & -1457 to -225 & $.008 *$ \\
\hline
\end{tabular}

$n$ sample size, $C I$ confidence interval

${ }^{\mathrm{a}}$ General exclusion criteria were applied

${ }^{*} p<.025$ (Bonferroni corrected $\alpha$ value) 
methods (binary response filter, payment cards and openended response format). Within each questionnaire version, all scenarios were randomized to control for order effects. However, it is possible that recruitment method and the exclusion of incomplete answers has led to bias in the estimates. It should also be noted that using an ex-post perspective, as in the present study (i.e., respondents are asked to imagine having experienced a heart attack/depressive symptoms), usually results in lower WTP estimates than valuing WTP from an ex-ante perspective (where WTP is evaluated previous to the existence of the need; e.g., [36, 37]).

Additionally, the hypothetical scenarios in which the success of treatment is certain and will fully restore the respondents' initial health state-which is highly unlikely-may have led to overestimation of WTP estimates. More realistic health-gain scenarios with uncertainty characteristics should be evaluated in further research. As health insurance is mandatory in the German health care system, we included an introductory statement in accordance with Ahlert and colleagues [4] to emphasize the hypothetical scenario that such a mandatory health insurance does not exist. However, the use and wording of such introductory statements should further be evaluated. Results could also be influenced by respondents' perception that heart disease is associated with a higher reduction in quality of life and is more lethal than depressive disorders. We tried to maximize comparability of both health states by describing both health scenarios in a similar manner, including annual deaths by suicide for the depression questionnaire and annual deaths by heart attack for the heart disease questionnaire. Nevertheless, annual deaths by heart attack are approximately five times higher than deaths by suicide in Germany, which may have influenced WTP statements. Related studies should include a broader variety of versions of questionnaires, as proposed by Ahlert et al. [38], and should evaluate the wording of health-state descriptions. Additionally, an end-of-life scenario should be included, as it might be especially relevant in the development of governmental healthcare policies and decisions regarding the treatment of cardiovascular diseases.

External validity may be limited, as respondents from the public may not have been able to relate to the presented scenarios as well as patients who experience depressive disorders or heart diseases. Therefore, further research should investigate the effects of respondents' characteristics on WTP per QALY; specifically, if respondents with pre-existing depressive disorders or heart diseases are placing higher values on QALY gains for the respective health-state scenario. Caution is also needed in interpreting and generalizing the results of the present research. Recent studies indicate that WTP per QALY seems to depend on several differential contextual factors, such as the size of the QALY gain valued, illness type and severity (e.g., $[6,7])$, and the design and wording of the questions presented [38]. The present research supports the concluding remarks of recent studies: the assumption that "a QALY is a QALY is a QALY" and the determination of a uniform price threshold per QALY seem less than likely $[6,7]$. Therefore, caution is needed when transferring the values placed on QALY gains for heart disease and depression to other mental disorders or physical illnesses. In addition, we derive WTP per QALY based on individual preferences. From a societal perspective, and if WTP per QALY estimates are used for health care decisions, indirect health care costs (such as productivity loss and sick leave) should also be taken into consideration, possibly resulting in higher values per QALY gain [39].

\section{Conclusions}

Having presented respondents with different hypothetical QALY gains for a mental or physical health scenario (depression and heart disease), this study supports previous findings that the determination of a uniform price threshold for a QALY gain may not be suitable. Although recent studies have shown that WTP is not linearly proportional to the QALY gains valued, and that it may not be empirically attainable to estimate a single QALY value (e.g., [6, 7]), estimating a population's WTP per QALY may still be an important input for policy- and decision-makers, as it facilitates an understanding of the population's preferences regarding resource allocation. As concluded by Sund and Svensson [1], a specified threshold value per QALY based on state-of-the-art research may improve efficiency when deciding which treatment interventions to fund or reimburse. $^{2}$

Supplementary Information The online version contains supplementary material available at https://doi.org/10.1007/s11136-021-02772-x.

Acknowledgements We would like to thank Katharina Bode, $\mathrm{PhD}$, for conceptual advisement, Lars Paternoster and Robert Szczepanski for their help in implementing the questionnaire versions online and USUMA GmbH for recruitment of subjects.

Author contributions LU: Conceptualization, Statistical analysis, Methodology, Writing - original draft, review and editing. CK: Conceptualization, Methodology, Writing-review and editing. All authors contributed to and have approved the final manuscript.

Funding Open Access funding enabled and organized by Projekt DEAL. This research did not receive any specific grant from funding agencies in the public, commercial, or not-for-profit sectors.

\footnotetext{
${ }^{2}$ Such thresholds have been introduced for example in the United Kingdom and the Netherlands. For further information and a discussion of cost-effectiveness thresholds, readers are pointed to [40].
} 
Data availability The data that support the findings of this study are available on request from the corresponding author. The data are not publicly available due to privacy or ethical restrictions.

\section{Compliance with ethical standards}

Conflict of interest The authors declare that they have no conflict of interest.

Ethical approval This study was performed in line with the principles of the Declaration of Helsinki. Approval was granted by the Ethics Committee of the University of Hildesheim (No. 7.18).

Open Access This article is licensed under a Creative Commons Attribution 4.0 International License, which permits use, sharing, adaptation, distribution and reproduction in any medium or format, as long as you give appropriate credit to the original author(s) and the source, provide a link to the Creative Commons licence, and indicate if changes were made. The images or other third party material in this article are included in the article's Creative Commons licence, unless indicated otherwise in a credit line to the material. If material is not included in the article's Creative Commons licence and your intended use is not permitted by statutory regulation or exceeds the permitted use, you will need to obtain permission directly from the copyright holder. To view a copy of this licence, visit http://creativecommons.org/licenses/by/4.0/.

\section{References}

1. Sund, B., \& Svensson, M. (2017). Estimating a constant WTP for a QALY - A mission impossible? European Journal of Health Econonics, 19, 871-880.

2. Brazier, J., Ratcliffe, J., Saloman, J., \& Tsuchiya, A. (2017). Measuring and valuing health benefits for economic evaluation (p. 10). Oxford: Oxford University Press.

3. Pennington, M., Baker, R., Brouwer, W., Mason, H., Hansen, D. G., Robinson, A., et al. (2015). Comparing WTP values of different types of QALY gain elicited from the general public. Health Economics, 24, 280-293.

4. Ahlert, M., Breyer, F., \& Schwettmann, L. (2013). What you ask is what you get: Willingness to pay for a QALY in Germany. CESifo Working Paper Series, 4239, 1-33.

5. Bobinac, A., van Exel, J., Rutten, F. F., \& Brouwer, W. B. (2014). The value of a QALY: Individual willingness to pay for health gains under risk. Pharmacoeconomics, 32, 75-86.

6. Ryen, L., \& Svensson, M. (2015). The willingness to pay for a quality adjusted life year: A review of the empirical literature. Health Economics, 24, 1289-1301.

7. Igarashi, A., Goto, R., \& Yoneyama-Hirozane, M. (2019). Willingness to pay for QALY: Perspectives and contexts in Japan. Journal of Medical Economics, 22, 1041-1046.

8. World Health Organization. (2008). The global burden of disease: 2004 update. Geneva: World Health Organization.

9. World Health Organization. (2018). WHO methods and data sources for global burden of disease estimates 2000-2016. Retrieved August 29, 2019 from https://www.who.int/healthinfo /global_burden_disease/GlobalDALY_method_2000_2016. pdp?ua $=1$.

10. Hay, S. I., Abajobir, A. A., Abate, K. H., Abbafati, C., Abbas, K. M., Abd-Allah, F., et al. (2017). Global, regional, and national disability-adjusted life-years (DALYs) for 333 diseases and injuries and healthy life expectancy (HALE) for 195 countries and territories, 1990-2016: A systematic analysis for the global burden of disease study 2016. The Lancet, 390, 1260-1344.

11. Murray, C. J., Vos, T., Lozano, R., Naghavi, M., Flaxman, A. D., Michaud, C., et al. (2012). Disability-adjusted life years (DALYs) for 291 diseases and injuries in 21 regions, 1990-2010: A systematic analysis for the global burden of disease study 2010. The Lancet, 380, 2197-2223.

12. World Health Organization. (2019). Cardiovascular diseases. Retrieved January 9, 2020 from https://www.who.int/news-room/ fact-sheets/detail/cardiovascular-diseases-(cvds).

13. Joseph, P., Leong, D., Mckee, M., Anand, S. S., Schwalm, J. D., Teo, K.,..., Yusuf, S. (2017). Reducing the global burden of cardiovascular disease, part 1: The epidemiology and risk factors. Circulation Research, 121, 677-694.

14. World Health Organization. (2017). Cardiovascular diseases. Retrieved December 10, 2020 from https://www.who.int/en/ news-room/fact-sheets/detail/cardiovascular-diseases-(cvds).

15. Tomonaga, Y., Haettenschwiler, J., Hatzinger, M., HolsboerTrachsler, E., Rufer, M., Hepp, U., \& Szucs, T. D. (2013). The economic burden of depression in Switzerland. Pharmacoeconomics, 31, 237-250.

16. Mozaffarian, D., Benjamin, E. J., Go, A. S., Arnett, D. K., Blaha, M. J., Cushman, M.,..., Howard, V.J. (2016). Heart disease and stroke statistics-2016 update a report from the American Heart Association. Circulation, 133, e38-e48

17. Greenberg, P. E., Fournier, A. A., Sisitsky, T., Pike, C. T., \& Kessler, R. C. (2015). The economic burden of adults with major depressive disorder in the United States (2005 and 2010). Journal of Clinical Psychiatry, 76, 155-162.

18. Szende, A., Oppe, M., \& Devlin, N. J. (2007). EQ-5D value sets: Inventory, comparative review and user guide. Dordrecht: Springer.

19. Dolan, P., Gudex, C., Kind, P., \& Williams, A. A. (1999). Social tariff for EuroQoL. Results from a UK general population survey (p. 138). York: Centre for Health Economics, University of York.

20. Kroenke, K., Spitzer, R. L., \& Williams, J. B. (2003). The patient health questionnaire-2: Validity of a two-item depression screener. Medical Care, 41, 1284-1292.

21. EuroVaQ Team. (2010). European value of a quality adjusted life year-Final publishable report. Retrieved October 7, 2019 from http://research.ncl.ac.uk/eurovaq/EuroVaQ_Final_Publishabl e_Report_and_Appendices.pdf.

22. Olsen, J. A., \& Donaldson, C. (1998). Helicopters, hearts and hips: Using willingness to pay to set priorities for public health care programmes. Social Science and Medicine, 46, 1-12.

23. Ng, E. S., Grieve, R., \& Carpenter, J. R. (2013). Two stage nonparametric bootstrap sampling with shrinkage correction for clustered data. Stata Journal, 13, 141-164.

24. Field, A. (2018). Discovering statistics using IBM SPSS statistics (5th ed.). London: Sage.

25. Rosenthal, R. (1991). Meta-analytic procedures for social research (2nd ed.). Newbury Park, CA: Sage.

26. DGPPN, BÄK, KBV, AWMF, AkdÄ, BPtK, BApK, DAGSHG, DEGAM, DGPM, DGPs, DGRW (Hrsg.) für die Leitliniengruppe Unipolare Depression*. S3-Leitlinie/Nationale VersorgungsLeitlinie Unipolare Depression-Leitlinien-report, 2. Auflage. 2015. Version 4. Retrieved October 1, 2020 from www.depression .versorgungsleitlinien.de.

27. Timäus, C., Vogelgsang, J., Kis, B., Radenbach, K., Wolff-Menzler, C., Mavridou, K.,... \& Wiltfang, J. (2020). Current clinical practice of electroconvulsive therapy and repetitive transcranial magnetic stimulation in psychiatry, a German sample. European Archives of Psychiatry and Clinical Neuroscience, 1-10.

28. Loh, N., Nickl-Jockschat, T., Sheldrick, A. J., \& Grözinger, M. (2013). Accessibility, standards and challenges of 
electroconvulsive therapy in Western industrialized countries: A German example. The World Journal of Biological Psychiatry, 14, 432-440.

29. Nordanskog, P., Hultén, M., Landén, M., Lundberg, J., von Knorring, L., \& Nordenskjöld, A. (2015). Electroconvulsive therapy in Sweden 2013: Data from the national quality register for ECT. The Journal of ECT, 31, 263.

30. Wiesing, U., \& Fallgatter, A. J. (2018). Rationalität und Freiheit in der Medizin: Der Fall der Elektrokrampftherapie (Rationality and freedom in medicine: The case of electroconvulsive therapy). Der Nervenarzt, 89, 1248-1253.

31. Arnaez, J. M., Krendl, A. C., McCormick, B. P., Chen, Z., \& Chomistek, A. K. (2019). The association of depression stigma with barriers to seeking mental health care: A cross-sectional analysis. Journal of Mental Health, 29, 1-9.

32. Blanco, C., Okuda, M., Wright, C., Hasin, D. S., Grant, B. F., Liu, S. M., \& Olfson, M. (2008). Mental health of college students and their non-college-attending peers: Results from the national epidemiologic study on alcohol and related conditions. Archives of General Psychiatry, 65, 1429-1437.

33. Thornicroft, G. (2007). Most people with mental illness are not treated. The Lancet, 370, 807-808.

34. Henderson, C., Evans-Lacko, S., \& Thornicroft, G. (2013). Mental illness stigma, help seeking, and public health programs. American Journal of Public Health, 103, 777-780.
35. Gyrd-Hansen, D., Jensen, M. L., \& Kjaer, T. (2014). Framing the willingness-to-pay question: Impact on response patterns and mean willingness to pay. Health Economics, 23, 550-563.

36. Neumann, P. J., \& Johannesson, M. (1994). The willingness to pay for in vitro fertilization: A pilot study using contingent valuation. Medical Care, 32, 686-699.

37. Johannesson, M. (1996). A note on the relationship between ex ante and expected willingness to pay for health care. Social Science \& Medicine, 42, 305-311.

38. Ahlert, M., Breyer, F., \& Schwettmann, L. (2016). How you ask is what you get: Framing effects in willingness-to-pay for a QALY. Social Science and Medicine, 150, 40-48.

39. Huang, L., Frijters, P., Dalziel, K., \& Clarke, P. (2018). Life satisfaction, QALYs, and the monetary value of health. Social Science and Medicine, 211, 131-136.

40. Brouwer, W., van Baal, P., van Exel, J., \& Versteegh, M. (2019). When is it too expensive? Cost-effectiveness thresholds and health care decision-making. European Journal of Health Economics, 20, 175-180.

Publisher's Note Springer Nature remains neutral with regard to jurisdictional claims in published maps and institutional affiliations. 